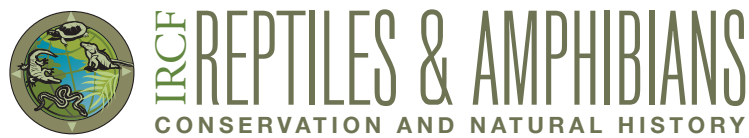

\section{New Distribution Record and Intergeneric Amplexus in the Malabar Tree Toad, Pedostibes tuberculosus Günther 1875 (Amphibia: Anura: Bufonidae)}

\author{
Amit Sayyed and Abhijit Nale
}

Wildlife Protection and Research Society, India (amitsayyedsatara@gmail.com \& abhijeetnale443@gmail.com)

\author{
Photographs by the senior author
}

$\mathrm{T}$ he Malabar Tree Toad (Pedostibes tuberculosus) was initially described by Günther in 1875 from Kerala, India. The body is slender, the head of moderate size, snout pointed, lores vertical, fingers moderate, depressed, and webbed at the base, the first finger is half the length of the second, toes are almost entirely webbed, and tips of both fingers and toes are dilated into broad, truncated disks that are smaller on the toes, and the tubercle near the joint is small, with two small, flat metatarsal tubercles. Coloration in life is brownish above, sides are dark with white bands running from below the eyes

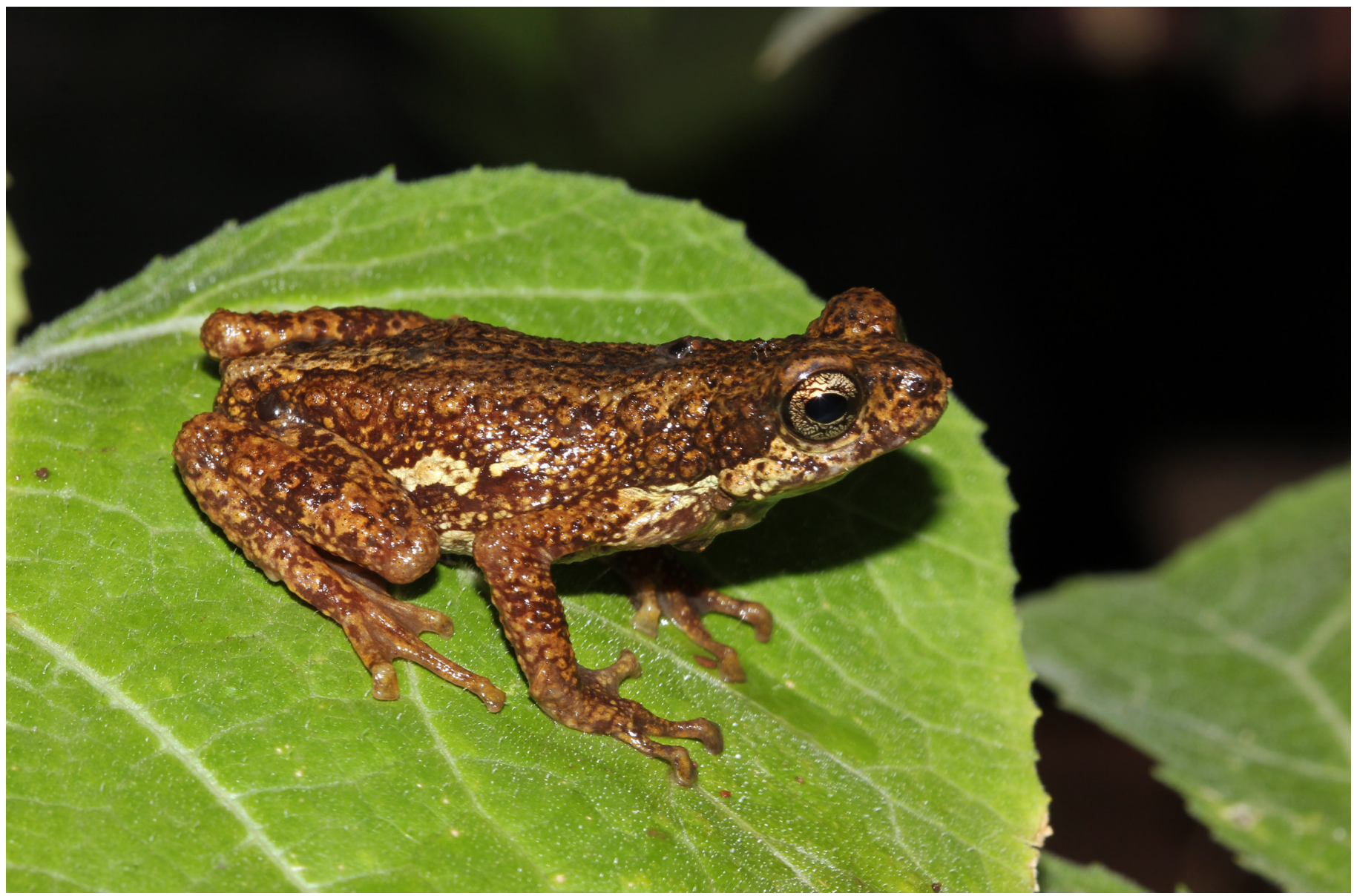

Fig. 1. Malabar Tree Toad (Pedostibes tuberculosus) at the Koyna Wildlife Sanctuary, Satara District, Maharashtra, India (elevation $921.5 \mathrm{~m}$ ). 
to the axilla, an additional white, longitudinal band in the lumbar region, and a dark-spotted venter.

Pedostibes tuberculosus is endemic to the Western Ghats of India. It is listed as Endangered on the IUCN Red List (Biju et al. 2004). The species had not been reported from any part of its known range for a span of more than 100 years since its description until it was rediscovered in 1980 by S.K. Bhattacharya in the Silent Valley National Park (Pillai 1986). It subsequently has been reported from various locations in the southern Western Ghats: Palakkad, Ponmudi, Thiruvananthapuram, Vannathimala, Wayanad, the Aralam Wildlife Sanctuary, and Kannur in Kerala; the Cotegao Wildlife Sanctuary, Mollem Goa, Kalakkad, Tirunelveli Tamil Nadu, and at Jakkanagadde, the Sharavathi River basin, Shimoga, and Kudremukh National Park in Karnataka (Dahanukar et al. 2004; Gururaja and Ramachandra 2006; Dinesh and Radhakrishnan 2008).

On 18 August 2016, we encountered Pedostibes tuberculosus (Fig. 1) during an amphibian survey at the Koyna Wildlife Sanctuary, Satara District, Maharashtra at an elevation of $921.5 \mathrm{~m}$. This is the first report of the species from Maharashtra. Extensive field surveys are needed to better understand the distribution of these toads in the northern Western Ghats; they also are likely to occur within the Koyna Wildlife Sanctuary, as well as Chandoli National Park,
Radhanagari, and in parts of Amboli and the Tilari region of Maharashtra.

Rainfall was continuous during the survey. At $1930 \mathrm{~h}$ males were calling from the trees, on the ground, and from the edges of a pond; we recorded calls with a PCM recorder 44 at $100 \mathrm{~Hz}$. The small population was restricted to the immediate vicinity of the small natural pond near a stream, which was surrounded with large trees in dense forest. We observed a few amplecting pairs (Fig. 2), eggs laid at the edges of the pond (Fig. 3), and noted the presence of three other anuran species: Ghate's Shrub Frogs (Raorchestes ghatei) and widely distributed Common Indian Treefrogs (Polypedates maculatus) and Asian Common Toads (Duttaphrynus melanostictus).

During that same survey, we noticed intergeneric amplexus of $P$. tuberculosus and D. melanostictus. In the first instance, a male $P$. tuberculosus was in amplexus with a female D. melanostictus (Fig. 4). A second sighting involved two male $P$. tuberculosus attempting to mate with a single female $D$. melanostictus (Fig. 5). Sayyed (2013) had reported intergeneric amplexus when a male Malabar Gliding Frog (Rhacophorus malabaricus) attempted to mate with a female Polypedates maculatus. A photograph on social media shows a male Kalakkad Treefrog (Rhacophorus calcadensis) in amplexus with a female R. malabaricus (P. Manoj, 2015, https://www.facebook.com/ photo.php?fbid=1159696284047865\&set=a. 7305917736

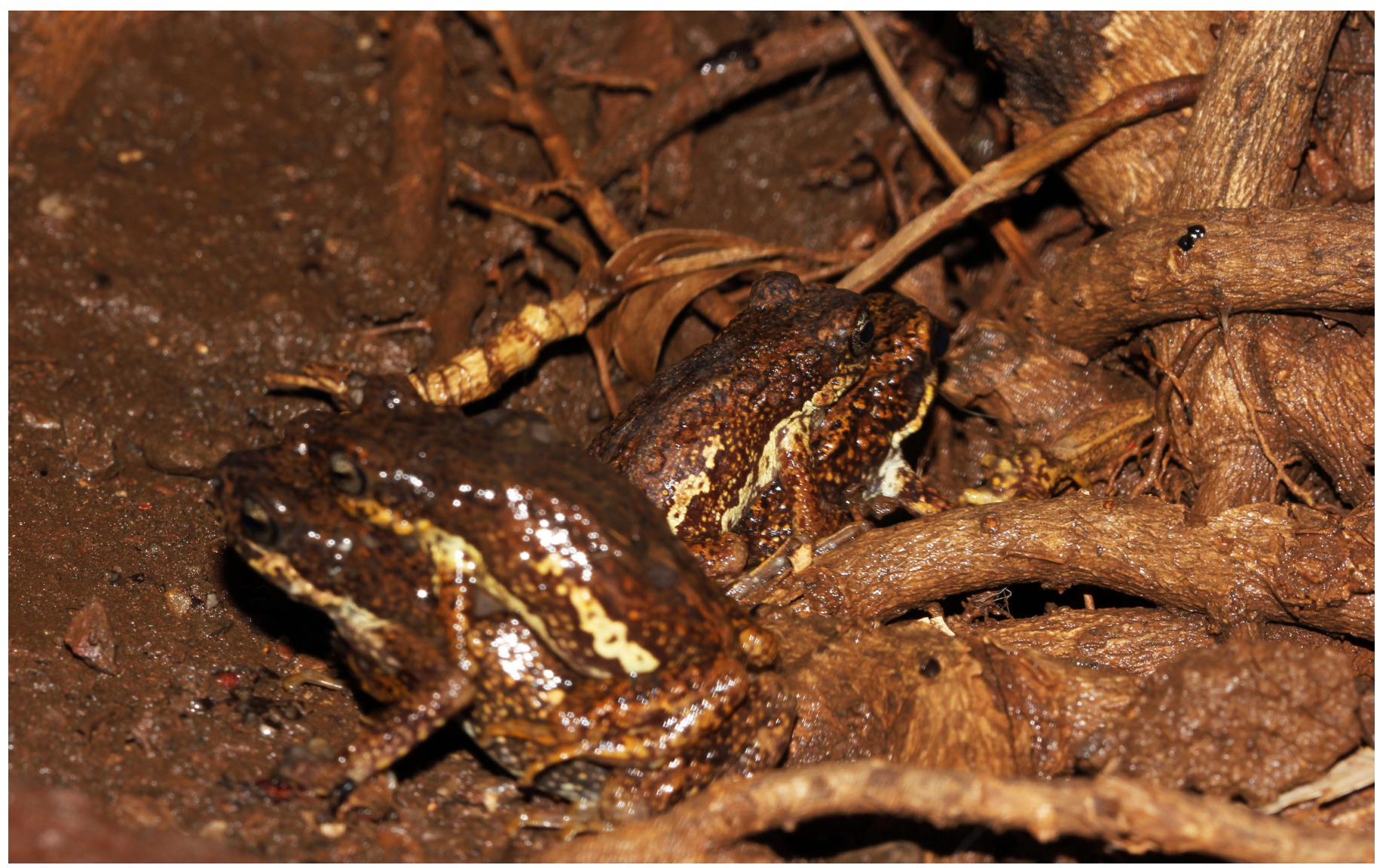

Fig. 2. Amplecting pairs of Malabar Tree Toads (Pedostibes tuberculosus) at the Koyna Wildlife Sanctuary, Satara District, Maharashtra, India. 


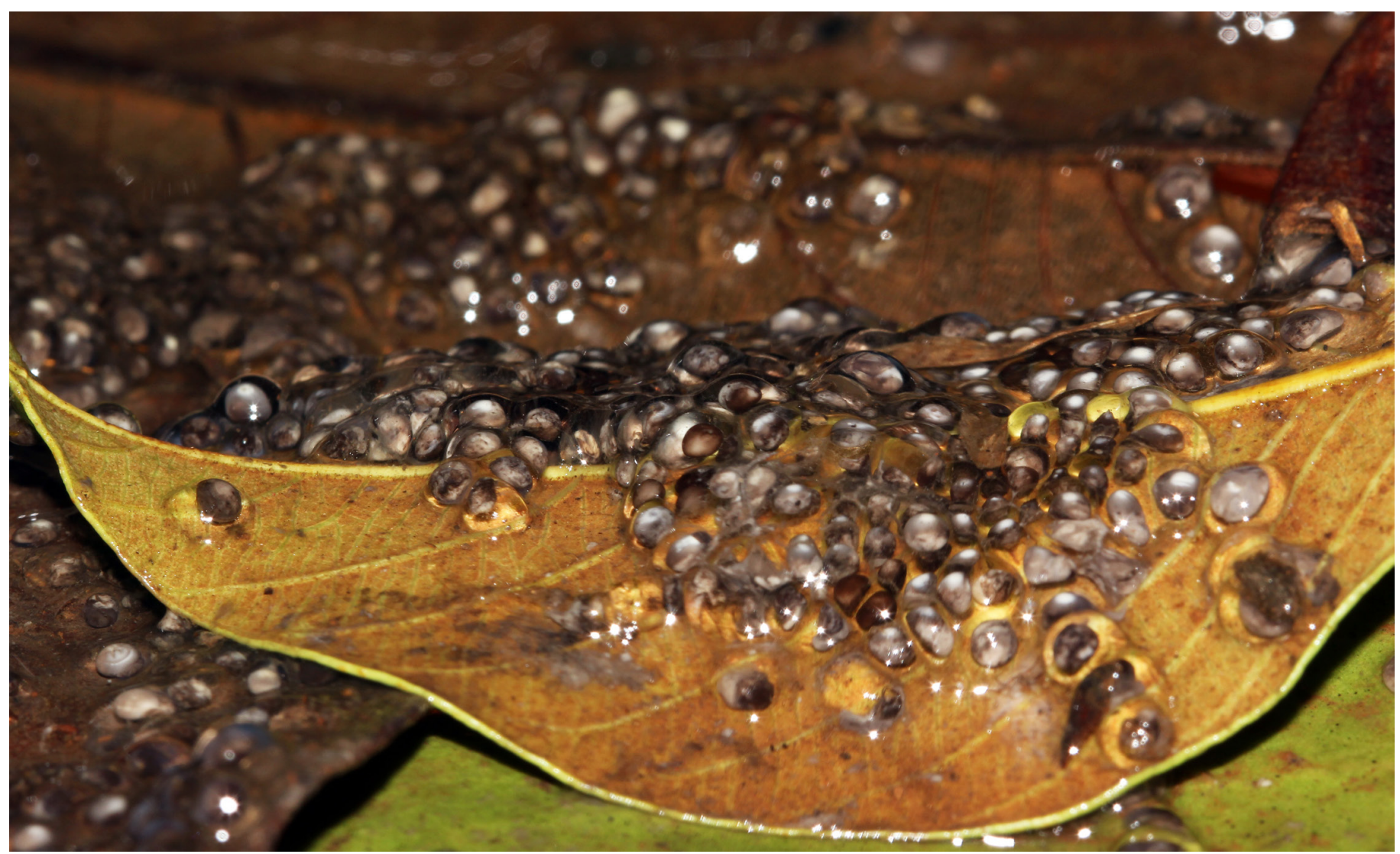

Fig. 3. Eggs of the Malabar Tree Toad (Pedostibes tuberculosus) laid at the edge of a pond in the Koyna Wildlife Sanctuary, Satara District, Maharashtra, India.

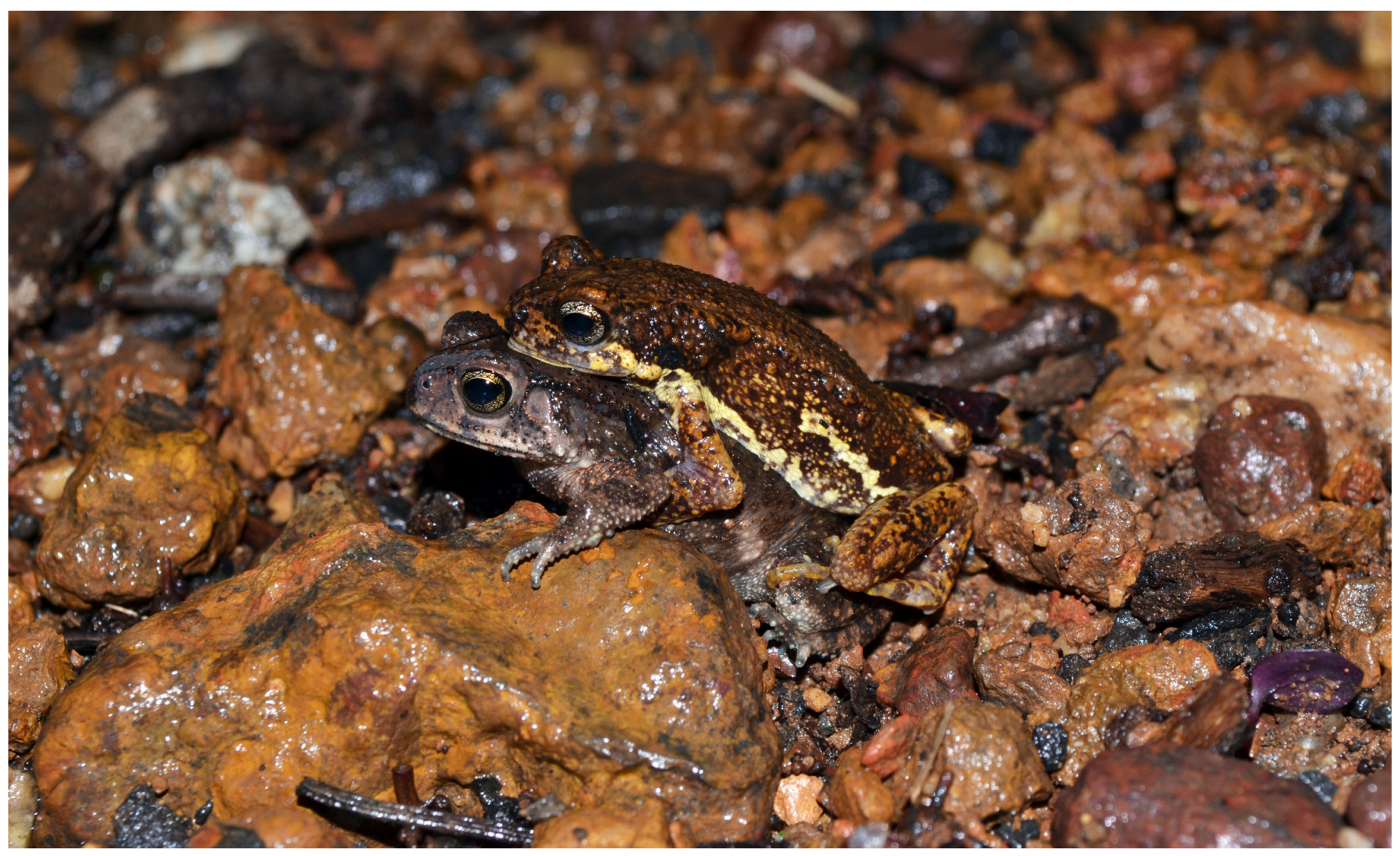

Fig. 4. Intergeneric amplexus between a male Malabar Tree Toad (Pedostibes tuberculosus) and a female Asian Common Toad (Duttaphrynus melanostictus). 


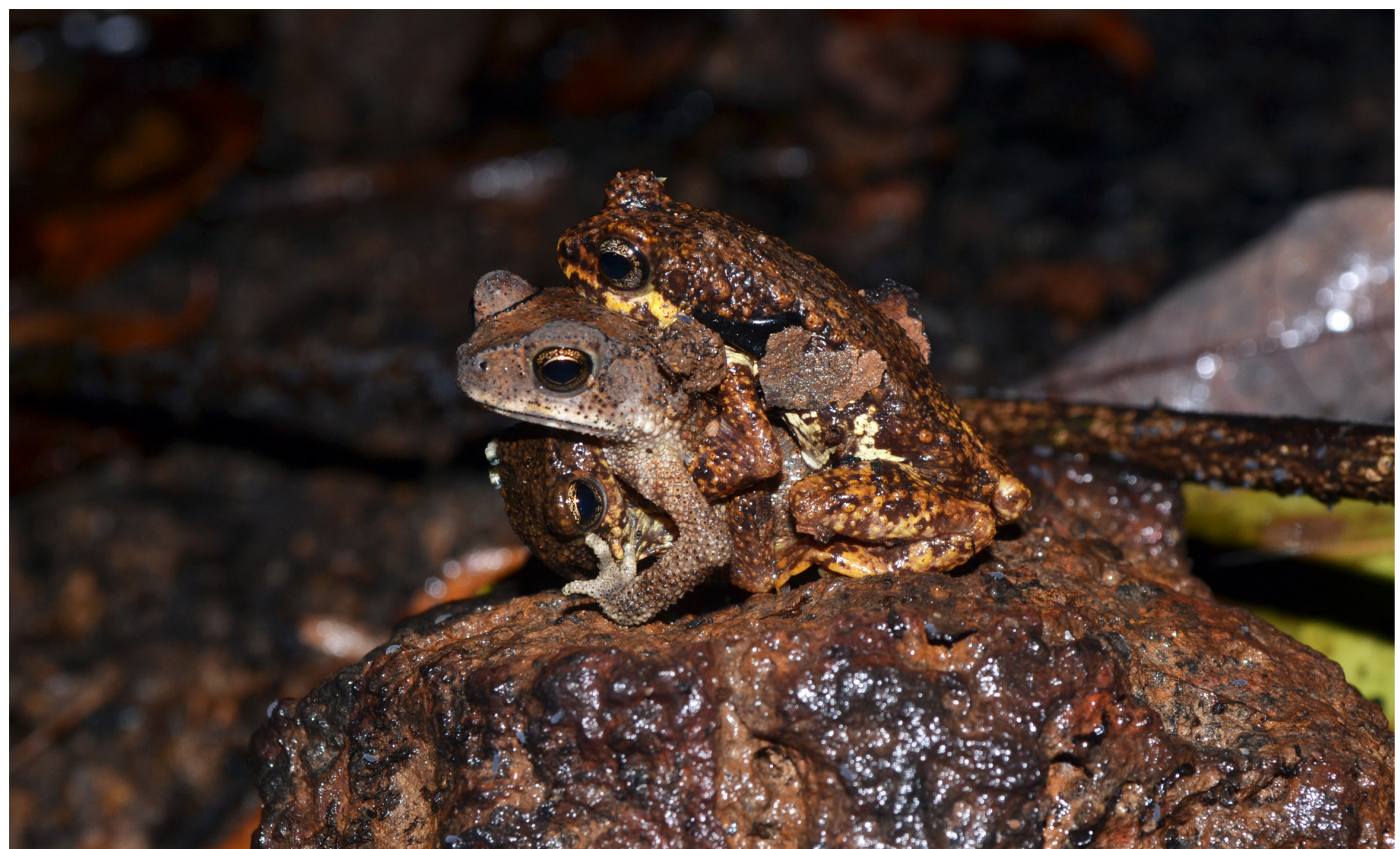

Fig. 5. Attempted intergeneric amplexus of two male Malabar Tree Toads (Pedostibes tuberculosus) and a female Asian Common Toad (Duttaphrynus melanostictus).

\subsubsection{1\&type=3\&permP} age $=1$ ). Such observations suggest that attempted interspecific amplexus between congeners and even confamilial species is a relatively common event. Contributing factors could be stress triggered by competition for breeding sites or even a disproportionate number of females at some locations. However, males of many anuran species often are indiscriminant when mating (e.g., Engeler and Reyer 2001), and these records might merely illustrate that lack of selectivity and should not be construed as hybridization between the species involved.

\section{Acknowledgments}

We thank Dr. K.V. Gururaja for helpful suggestions, and Devendra Bhosle and Ashitosh Suryavanshi, members of the Wildlife Protection and Research Society, for help with fieldwork.

\section{Literature Cited}

Biju, S.D., S. Dutta, R. Inger and V.A. Gour-Broome. 2004. Pedostibes tuberculosus. The IUCN Red List of Threatened Species 2004: e.T16470A5918772.

Dahanukar, N., A.D. Padhye, G.P. Salelkar, and H.V. Ghate. 2004. Aktueller Beleg für die Malabar Baumkröte, Pedostibes tuberculosus Gunther, 1876, in Indien. Sauria 26(3): 17-20.

Dinesh, K.P. and C. Radhakrishnan. 2008. New site records of the Malabar Tree Toad, Pedostibes tuberculosus Gunther (Amphibia: Anura: Bufonidae), in Western Ghats, India. Records of the Zoological Survey of India 108: 13-15.

Engeler, B. and H.-U. Reyer. 2001. Choosy females and indiscriminate males: Mate choice in mixed populations of sexual and hybridogenetic water frogs (Rana lessonae, Rana esculenta). Behavioral Ecology 12: 600-606.

Gururaja, K.V. and T.V. Ramachandra. 2006. Pedostibes tuberculosus (Malabar Tree Toad). Advertisement call and distribution. Herpetological Review 37: 75-76.

Sayyed, A. 2013. Note on the natural crossbreeding in Family Rhacophoridae, Anura, Amphibia. Ela Journal 2(3): 7-9.

Pillai, R.S. 1986. Amphibian fauna of Silent Valley, Kerala, S. India. Records of the Zoological Survey of India 84: 229-242. 